IMECE2005-80400

\title{
PVDF AND PZT PIEZOELECTRIC WAFER ACTIVE SENSORS FOR STRUCTURAL HEALTH MONITORING
}

\author{
Bin Lin, Member ASME \\ Department of Mechanical Engineering \\ University of South Carolina \\ Columbia, SC 29208 \\ 803.777.1535, linbin@engr.sc.edu
}

\author{
Victor Giurgiutiu, PhD, PE, Member ASME \\ Department of Mechanical Engineering \\ University of South Carolina \\ Columbia, SC 29208 \\ 803.777.8018, victorg@sc.edu
}

\begin{abstract}
Piezoelectric wafer active sensors (PWAS) used in structural health monitoring (SHM) applications are able to detect structural damage using Lamb waves. PWAS are small, lightweight, unobtrusive and inexpensive. PWAS achieve direct transduction between electric and elastic wave energies. PWAS are essential elements in the Lamb-wave SHM with pitch-catch, pulse-echo, phased array system and electromechanical impedance methods.

PWAS are charge mode sensors and they can be used as both transmitters and receivers. A model of PWAS is shown in this paper. In vibration, impact detections applications, the PWAS response is strong due to the large dynamic change of strain. In pitchcatch, pulse-echo and phased array applications, PWAS are used to generate and receive Lamb waves and the PWAS response is small. A charge amplifier for PWAS applications is introduced in this paper.

PWAS are normally made of piezoceramic Lead Zirconate Titanate (PZT). The structural integrity tests require attachment of PWAS to the material surface and there are critical applications where the rigid piezoceramic wafers cannot conform to curved surfaces. As alternative one can use flexible piezopolymer such as polyvinylidene fluoride (PVDF); such PVDF-PWAS have been studied in this paper. PVDF-PWAS were mounted on a cantilever beam for the free vibration test and on a long rod for the longitudinal impact test. The
\end{abstract}

experimental results of the PZT-PWAS and PVDFPWAS have been compared with the conventional strain gauge. The theoretical and experimental results in this study gave the basic demonstration of the piezoelectricity of PZT-PWAS and PVDF-PWAS.

\section{INTRODUCTION}

Structural health monitoring (SHM) addresses an urgent need of our aging infrastructure. In recent years, several investigators (Chang ${ }^{[1],[2]}$, Wang and Chang $^{[3]}$, Lin and Yuan ${ }^{[4],}{ }^{[5]}$, Ihn and Chang ${ }^{[6]}$,

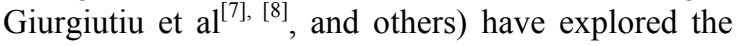
generation and detection of structural waves with piezoelectric wafer active sensors (PWAS). Most of the methods used in conventional NDE, such as pitch-catch, pulse-echo, and phased arrays, have also been demonstrated experimentally with PWAS (Giurgiutiu et al. ${ }^{[8],[9]}$ ). These successful experiments have positioned PWAS as an enabling technology for the development and implementation of active SHM systems. PWAS are inexpensive, non-intrusive, unobtrusive, and minimally invasive. They can be surface-mounted on existing structures, inserted between the layers of lap joints, or placed inside composite materials. Figure 1 shows an array of 7 $\mathrm{mm}$ square PWAS mounted on an aircraft panel, adjacent to rivet heads and an electric discharge machined (EDM) simulated crack. The minimally invasive nature of the PWAS devices is apparent. A PWAS is much lighter, smaller and cheaper in 
contrast a conventional ultrasonic transducer. PWAS are used in SHM applications and are able to detect structural damage using Lamb waves. PWAS achieve direct transduction between electric and elastic wave energies. PWAS are essential elements in Lambwave SHM with pitch-catch, pulse-echo, and electromechanical impedance methods. PWAS can be made from piezoceramics, piezocomposite, or piezopolymers.

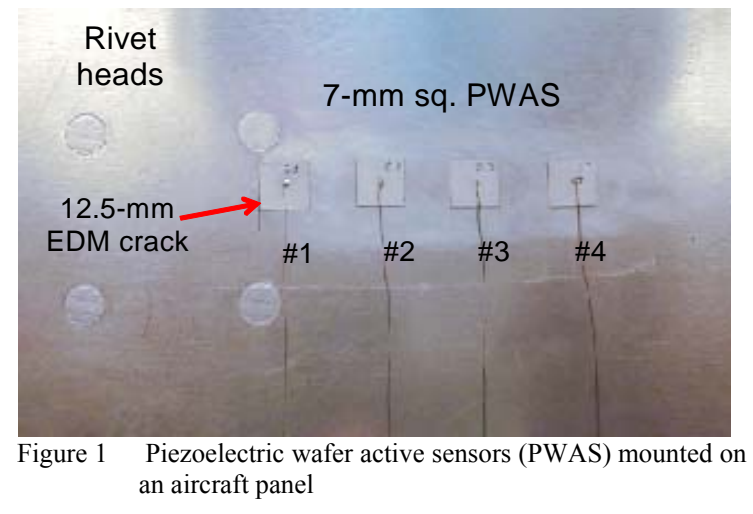

The most common used PWAS are made of piezoceramics (e.g., lead zirconate titanate, a.k.a. PZT). Piezoceramics are typically made of simple perovskites and solid solution perovskite alloys. Mechanical compression or tension on a poled piezoelectric ceramic element changes the dipole moment, creating a voltage. Compression along the direction of polarization, or tension perpendicular to the direction of polarization, generates voltage of the same polarity as the poling voltage. Brittle piezoceramic PWAS can withstand very small bending. This brittleness imposes difficulties in handling and bonding of the PWAS into the structure being monitored. In addition, piezoceramic PWAS have poor conformability to curved surfaces and local straightening of the structural surface is required for PWAS installation ${ }^{[10],[11],[12]}$.

Piezopolymers (e.g., polyvinylidene fluoride, a.k.a. PVDF) are a class of piezoelectric materials that display piezoelectric properties similar to those of quartz and piezoceramics ${ }^{[15]}$. PVDF are supplied in the form of thin films that are flexible and show large compliance. Piezoelectric polymers are less expensive and easier to fabricate than piezoceramics. The flexibility of PVDF-PWAS overcomes some of the drawbacks associated with the brittleness of the piezoelectric ceramics

When PWAS are used as active sensors to generate and receive the Lamb wave, the receive signal is small and has a lot of noises especially when the test structure is thick. Traditionally, the wideband amplifiers are used to provide a high input voltage to generate stronger Lamb waves but the input voltage can not beyond the PWAS voltage limitation. A more efficient way is to amplify the PWAS output signals. The principle of a charge amplifier for PWAS applications is introduced in detail below and the experiment results agree very well with the theory model of this charge amplifier.

\section{MODELING}

\section{Linear PIEZoelectricity EQUATION}

In conventional ultrasonics, guided waves are generated by impinging the structural surface obliquely with an ultrasonic beam from a relatively large ultrasonic transducer affixed to a wedge. Snell's law ensures mode conversion at the interface, hence a combination of pressure and shear waves are simultaneously generated into the structure. If the structure is thin walled, guided plate or shell waves are being created. Alternatively, guided waves can be generated with a comb transducer, having comb spacing tuned with the guided-wave half wavelength. However, these conventional Lamb-wave probes (wedge and comb transducers) are relatively heavy, bulky, and expensive. In recent years, piezoelectric wafers permanently attached to the structure have been used for the guided waves generation and detection. PWAS operated on the piezoelectric principle that couples the electrical and mechanical variables in the material mechanical strain, $\left(S_{i j}\right)$, mechanical stress, $\left(T_{i j}\right)$, electrical field, $\left(E_{k}\right)$, and electrical displacement $\left(D_{j}\right)$ in the form:

$$
\begin{aligned}
& S_{i j}=s_{i j k l}^{E} \cdot T_{k l}+d_{k i j} \cdot E_{k} \\
& D_{j}=d_{j k l} \cdot T_{k l}+\varepsilon_{j k}^{T} \cdot E_{k}
\end{aligned}
$$

where $s_{i j k l}^{E}$ is the mechanical compliance of the material measured at zero electric field, $\varepsilon_{j k}^{T}$ is the dielectric permittivity measured at zero mechanical stress, and $d_{k i j}$ represents the piezoelectric coupling effect. For embedded NDE applications, PWAS couple their in-plane motion, excited by the applied oscillatory voltage through the piezoelectric effect, with the Lamb-waves particle motion on the material surface. Lamb waves can be either quasi-axial $\left(S_{0}\right.$, $\left.\mathrm{S}_{1}, \mathrm{~S}_{2}, \ldots\right)$, or quasi-flexural $\left(\mathrm{A}_{0}, \mathrm{~A}_{1}, \mathrm{~A}_{2}, \ldots\right)$.

\section{PWAS ACTUATOR}

Consider a piezoelectric wafer of length $l$, width $b$, and thickness $h$ that is undergoing longitudinal expansion $\left(u_{1}\right)$ induced by the thickness polarization electric field, $\left(E_{3}\right)$ (Figure 2). The electric field is produced by the application of a harmonic voltage, $V(t)=\hat{V} e^{i \omega t}$, between the top and bottom surfaces 
(electrodes). Assume that the length, width and thickness have widely separated values $(\mathrm{h}<<\mathrm{b}<<\mathrm{l})$ such that the length, width and thickness motions are practically uncoupled. Under the one-dimensional assumptions, the general constitutive equations reduce to the simpler expressions

$$
\begin{aligned}
& S_{1}=s_{11} \cdot T_{1}+d_{31} \cdot E_{3} \\
& D_{3}=d_{31} \cdot T_{1}+\varepsilon_{33} \cdot E_{3}
\end{aligned}
$$

At zero mechanical stress $T_{1}$, the actuated strain is,

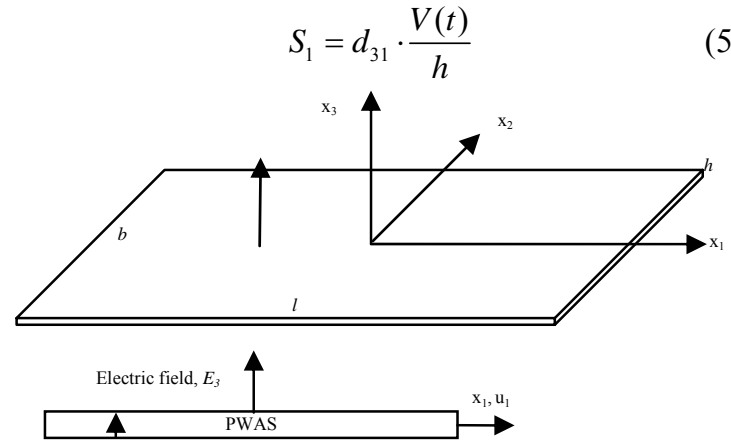

Figure 2 Schematic of a piezoelectric active sensor

\section{PWAS SENSOR}

PWAS sensor in dynamic regime was also analyzed by using one-dimensional assumptions. If a PWAS that is undergoing longitudinal expansion $\left(u_{1}\right)$ (Figure 3), the result voltage is harmonic with frequency $\omega$ when vibration is harmonic with natural frequency $\omega$.

For compactness, the notation used:

$$
\frac{\partial}{\partial t}()=(\dot{)})
$$

For harmonic voltage, $\dot{V}=i \omega V$.

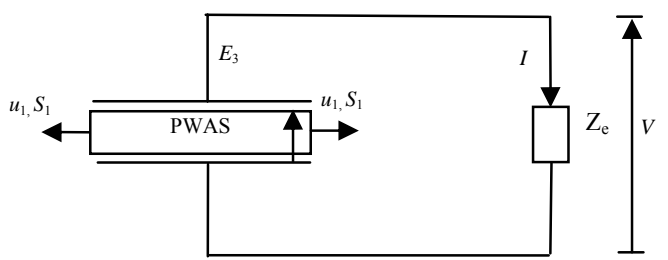

Figure 3 Schematic of a PWAS connected with measurement equipment (Resistance $Z_{\mathrm{e}}$ )

Consider the harmonic dynamic regime under the one-dimensional assumptions; the general constitutive equations are reduced to the simpler expressions:

$$
\begin{aligned}
& \dot{S}_{1}=s_{11} \cdot \dot{T}_{1}+d_{31} \cdot \dot{E}_{3} \\
& \dot{D}_{3}=d_{31} \cdot \dot{T}_{1}+\varepsilon_{33} \cdot \dot{E}_{3}
\end{aligned}
$$

When PWAS is under harmonic strain and connected with external measurement equipment, it will generate an $\mathrm{AC}$ current in circuit. The $\mathrm{AC}$ current can be expressed by using:

$$
\begin{aligned}
& I=\dot{D}_{3} \cdot A \\
& I=V \cdot Y_{e}
\end{aligned}
$$

where $Y_{e}$ is the external admittance, and $\mathrm{A}$ is the PWAS surface area $A=l \cdot b$.

Using Kirchhoff's current law for a closed circuit, we obtain the relation between voltage and stress:

$$
V=\frac{A \cdot d_{31}}{Y_{e}+Y_{0}} \dot{T}_{1}
$$

where $Y_{0}$ is PWAS admittance $Y_{0}=i \omega \varepsilon_{33} \frac{A}{h}$.

From equation(3), we obtain

$$
\dot{T}_{1}=\frac{1}{s_{11}}\left(\dot{S}_{1}+\frac{d_{31}}{h} \dot{V}\right)
$$

Finally we obtain the resulted voltage from the strain:

$$
V=\frac{1}{Y_{e}+\left(1-k_{31}^{2}\right) Y_{0}} \cdot A \frac{d_{31}}{s_{11}} \dot{S_{1}}
$$

where $k_{31}$ is the electromechanical coupling coefficient.

\section{PWAS CHARGE AMPLIFIER}

In pitch-catch, pulse-echo and phased array applications, PWAS are used to generate and receive Lamb waves and the PWAS response is small. We need to use amplifier to get a good signal. High voltage amplifier can be use to provide a high excitation signal to transmitter. The typical PWAS voltage limitation is in the range between $-30 \mathrm{~V}$ and $+120 \mathrm{~V}$. An efficient way to amplify the signal is to use the charge amplifier after the receiver PWAS. The charge amplifier principle was patented by W.P. Kistler in 1950 and gained practical significance in the $1960 \mathrm{~s}^{[22]}$. Basically a charge amplifier consists of a high gain inverting voltage amplifier at its input to achieve high insulation resistance. PWAS measuring systems are active electrical systems. That is, PWAS produce electrical output signals only when they experience a change in load. PWAS can be considered as a charge mode device with a capacitor $\mathrm{C}_{\text {PWAS. }}$.

A PWAS charge amplifier is shown in Figure 4 including the wire resistance and inductance. In this simplified schematic, $V_{o}=$ output voltage; $C_{P W A S}=$ PWAS capacitance; $\mathrm{L}_{\text {wire }}=$ wire inductance; $\mathrm{C}_{\text {wire }}=$ wire resistance; $C_{f}=$ feedback capacitor; $R_{f}=$ time constant resistor; $Q=$ charge generated by PWAS. Charge amplifier voltage output for a static load,

$$
V_{o}=-\frac{Q_{P W A S}}{C_{f}}
$$




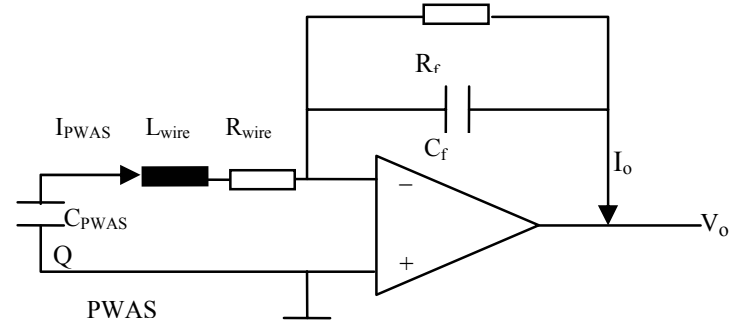

Figure 4 Schematic model of a charge amplifier consists of an op-amp amplifier and some passive components.

For a dynamic load,

$$
\begin{gathered}
I_{P W A S}=V_{P W A S} \frac{Y_{P W A S} \cdot Y_{\text {wire }}}{Y_{P W A S}+Y_{\text {wire }}} \\
I_{o}=-V_{o} Y_{f}
\end{gathered}
$$

where

$$
\begin{gathered}
Y_{P W A S}=j \omega C_{P W A S} \\
Y_{f}=j \omega C_{f}+\frac{1}{R_{f}} \\
Y_{\text {wire }}=\frac{1}{R_{\text {wire }}+j \omega L_{\text {wire }}}
\end{gathered}
$$

The relation between charge amplifier output voltage $\mathrm{V}_{\mathrm{o}}$ and PWAS output voltage $\mathrm{V}_{\text {PWAS }}$ is

$$
V_{o}=-\frac{Y_{P W A S} \cdot Y_{\text {wire }}}{Y_{f}\left(Y_{P W A S}+Y_{\text {wire }}\right)} V_{P W A S}
$$

\section{EXPERIMENTS}

\section{CANTILEVER BEAM FREE VibRATION}

Cantilever beams were well studied [18],[19]. A typical cantilever beam, used in this study, is $L=300$ mm long, $w=19.2 \mathrm{~mm}$ wide, and $t=3.23 \mathrm{~mm}$ thick. When the force, $\mathrm{P}$, is removed from a displaced beam, the beam will return to its original shape. However, inertia of the beam will cause the beam to vibrate around that initial location. According to the vibration and boundary equation, we can calculate the resonance frequency. The beam material is stainless steel 304 with density $8030 \mathrm{~kg} / \mathrm{m}^{3}$, and Young's modulus E $=195 \mathrm{Gpa}$. Theoretically, the first three nature frequency is $f_{1}=28.6 \mathrm{~Hz}, f_{2}=179 \mathrm{~Hz}$, and $f_{3}=501.3 \mathrm{~Hz}$. The measurement result is $f_{1}=$ $29.3 \mathrm{~Hz}, f_{2}=181.6 \mathrm{~Hz}$, and $f_{3}=502 \mathrm{~Hz}$.

The PZT-PWAS, PVDF-PWAS and strain gauge for dynamic measurement were investigated based on a vibration test setup show in Figure 5. The beam was mounted as a cantilever in a calibrated cantilever fixture. Two 7-mm square PVDF-PWAS with different thickness were placed on the top of the beam and a conventional 7-mm square PZT-PWAS and a strain gauge ware placed at the bottom of the beam (Figure 5).

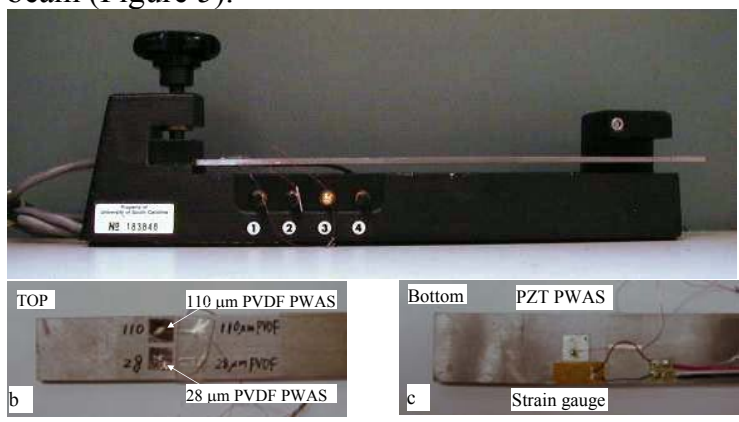

Figure 5 PZT-PWAS, PVDF-PWAS, and strain gauge on a cantilever beam: (a) experimental setup; (b) close-up view of the bottom surface showing the $200 \mu \mathrm{m}$ piezoelectric ceramic PWAS and strain gauge; (c) close-up view of the top surface showing the $28 \mu \mathrm{m}$ and $110 \mu \mathrm{m}$ PVDF-PWAS

The tip of the beam was displaced to a certain value (approx. $10 \mathrm{~mm}$ ) and then suddenly released as the beam entered in free vibration. A 4-channel Tektronix TDS5030B oscilloscope was used to collect the vibration response from different kind of sensors. Channel one was connected to the Vishay P3 strain indicator to record the electric signal generated by the resistance change in the strain gauge due to strain elongation. The other three channels were directly connected to the PZT-PWAS and PVDFPWAS to record the electric signals generated through the piezoelectric coupling between the mechanical vibration and the electric field. The recorded traces are shown in Figure 6.

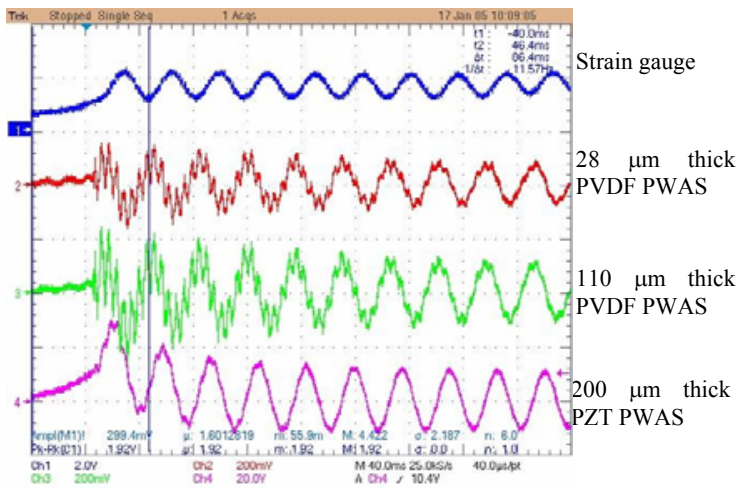

Figure 6 Vibration signal recorded by strain gauge, PVDFPWAS and PZT-PWAS.

The Fourier transform was used to analyze the frequency contents of the signals, which should correspond to the natural free vibration frequencies of the cantilever beam. The first three natural frequencies are shown to be $f_{1}=29.7 \mathrm{~Hz}, f_{2}=181$ $\mathrm{Hz}$, and $f_{3}=501 \mathrm{~Hz}$. The PZT-PWAS was found to give the highest voltage but it was less responsive to the higher frequencies. The PVDF-PWAS were 
found to be more responsive to the high frequencies but gave a lower voltage.

From Vishay P3 strain indicator and recorder, the peak to peak analog output was $1.32 \mathrm{~V}$ which means the peak to peak vibration strain equaled $338 \mu \varepsilon$. Assuming the oscilloscope's capacitance is $3 \mathrm{nF}$ and using the equation(13), the theoretical peak to peak voltage of PZT-PWAS, $110 \mu \mathrm{m}$ PVDF-PWAS and $28 \mu \mathrm{m}$ PVDF-PWAS are $30 \mathrm{~V}, 0.361 \mathrm{~V}$ and $0.346 \mathrm{~V}$ respectively. The experimental results were $30.8 \mathrm{~V}$, $0.508 \mathrm{~V}$ and $0.332 \mathrm{~V}$ respectively. The experimental response voltage (Table 1) and frequencies (Table 2) agreed with the theoretical prediction. The PWAS model can predict the strain and voltage relation.

Table 1 Comparison of PWAS response

\begin{tabular}{lcccc}
\hline & $\begin{array}{c}\text { PZT-PWAS } \\
(\mathrm{V})\end{array}$ & $\begin{array}{c}\text { 110mm PVDF- } \\
\text { PWAS (V) }\end{array}$ & $\begin{array}{c}28 \mathrm{~mm} \text { PVDF- } \\
\text { PWAS (V) }\end{array}$ \\
\cline { 1 - 1 } Theoretical & 30 & & 0.361 & .346 \\
Experimental & 30.8 & & 0.508 & 0.332 \\
Relative error (\%) & 2.67 & & 40.7 & -4.04 \\
\hline
\end{tabular}

Table 2 Comparison of Frequency

\begin{tabular}{lccc}
\hline & $\mathrm{f}_{1}(\mathrm{~Hz})$ & $\mathrm{f}_{2}(\mathrm{~Hz})$ & $\mathrm{f}_{3}(\mathrm{~Hz})$ \\
\cline { 2 - 4 } Theoretical & 28.6 & 179 & 501.3 \\
Experimental & 29.69 & 181.7 & 503.8 \\
Relative error (\%) & 3.81 & 1.51 & 0.50 \\
\hline
\end{tabular}

\section{LONG ROD IMPACTION TEST}

The PZT-PWAS, PVDF-PWAS and strain gauge for dynamic measurement was also investigated based on a long rod impact test. The longitudinal waves are generated by impacting the rod. The resulting waves are detected by using electrical resistance strain gages and PVDF-PWAS. PZTPWAS was not used in this case because it cannot fit on the curve surface of rod.

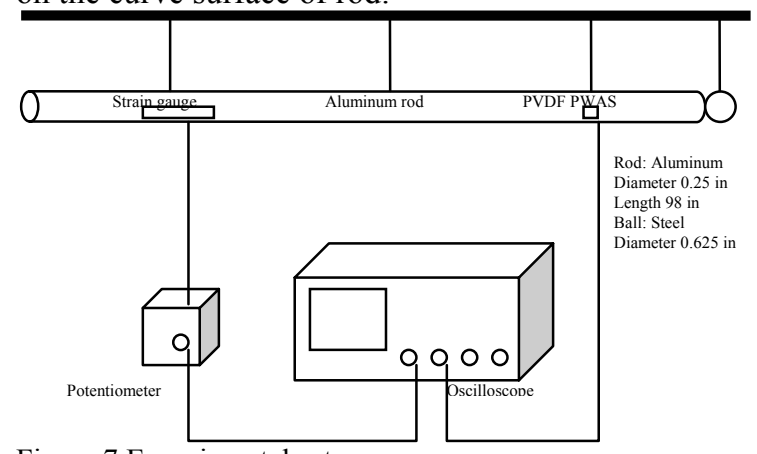

Figure 7 Experimental setup

A schematic of the apparatus is shown in Figure 7. A long rod is desirable so as to lengthen the time between reflections and make the pulses more distinct. The rod is suspended in three places by a monofilament line. One strain gage and three PVDFPWAS are used. The strain gauge is a BLH semiconductor type, mounted 23 inches from the left end of the rod. This type of strain gauge is selected for its high sensitivity good dynamic response. PVDF-PWAS are 7-mm square, cut from piezo film sheets provided by Measurement Specialties, Sensor Products Div. Three PVDF-PWAS have three different thicknesses, $28 \mu \mathrm{m}, 52 \mu \mathrm{m}$ and $110 \mu \mathrm{m}$, mounted 20 inches from the right end of the rod. The impactor is a 0.625 inch diameter steel ball supported by tow strings. The strings are adjustable so that the ball's center can be placed at the center of the end of the rod.

There are three types of waves that can be formed upon impact of a long rod; longitudinal waves, flexural waves and torsional waves. If the impact is axial, then the type of wave that is propagated is the longitudinal wave. The longitudinal wave speed propagate in a thin rod is $c=\sqrt{\frac{E}{\rho}}$ where $E$ and $\rho$ are the material's Young's modulus and density, respectively ${ }^{[20][21]}$. When the impactor hit the rod at time $\mathrm{T}_{0}$, the compression wave arrive the PVDFPWAS at time $T_{1}$, then arrive the strain gauge at time $\mathrm{T}_{1}$ '. When the compression wave reached the free end of the rod, it will be reflected as tension and vice versa. Stress reversal is a characteristic of the free end reflection. The tension wave will reach the strain gauge first at time $T_{2}$ and then reach the PVDFPWAS at time $T_{2}$. Then it will be reflected by the free end again as compression again.

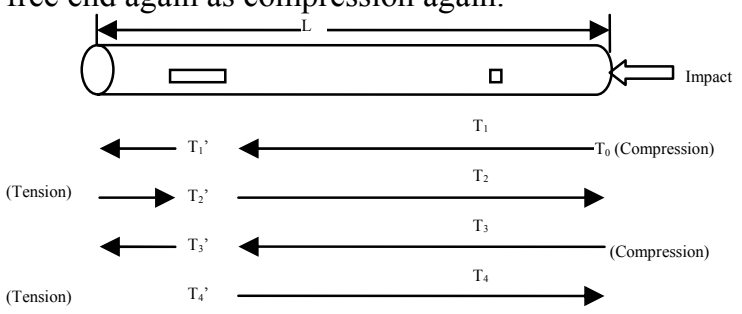

Figure 8 Stress wave propagation

Two pictures taken of the history of strain gauge and PVDF-PWAS are shown in Figure 9. The time base was $200 \mu$ s per division to allow recording of several transits of the wave pulse.

From the above test, three features are apparent for the long rod. First, each cycle contains a compressive peak for the PVDF-PWAS (positive) and for the strain gauge (negative). Second, each cycle contains a tensile peak from the reflected wave for the PVDF-PWAS (negative) and for the strain gauge (positive). Third, there is a dwell while the wave traverses the length of the rod. 


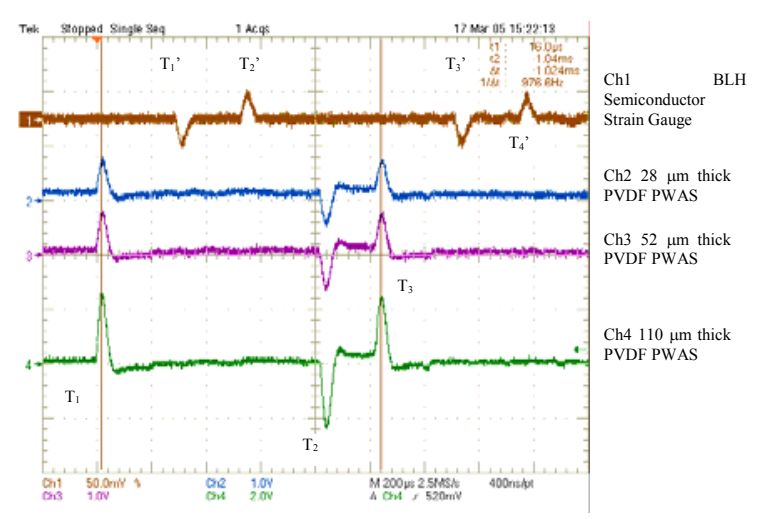

Figure 9 Impact responses for free-free boundary condition recorded by $(\mathrm{CH} 1)$ strain gauge; $(\mathrm{CH} 2) 28 \mu \mathrm{m}$ thick PVDF-PWAS; (CH 3) $52 \mu \mathrm{m}$ thick PVDFPWAS, (CH 4) $110 \mu \mathrm{m}$ thick PVDF-PWAS.

The rod is made of 6061-T6 aluminum alloy which the Young's modulus is $69 \mathrm{GPa}$ and the density is $2700 \mathrm{~kg} / \mathrm{m}^{3}$. The rod is 98 inches (2489 $\mathrm{mm})$ in length and 0.25 inch $(6.35 \mathrm{~mm})$ diameter. The theoretical wave speed is $\mathrm{c}=5055 \mathrm{~m} / \mathrm{s}$. The speed of the pulse moving up and down the rod can be estimated from the time between each peak. The distances traveled by the two adjacent positive or negative pulses are $2 \mathrm{~L}$, where $\mathrm{L}$ is the length of the rod. From Figure 10, the wave speed is $4860 \mathrm{~m} / \mathrm{s}$. The relative error is $3.8 \%$.

\section{PITCH-CATCH PZT-PWAS AND PVDF-PWAS EXPERIMENTS}

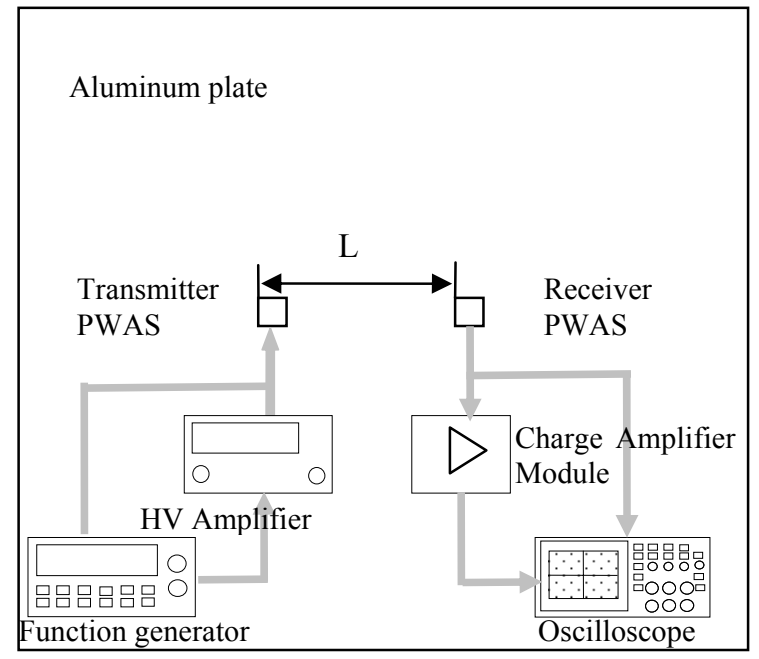

Figure 10 Two PWAS mounted on an aluminum plate; the left PWAS as a transmitter, the right PWAS as a receiver.

Two square PZT-PWAS (dimension: $7 \mathrm{~mm} \times 7$ $\mathrm{mm} \times 0.2 \mathrm{~mm}$ ) were attached to a $1200 \mathrm{~mm} \times$ $1100 \mathrm{~mm} \times 1.6 \mathrm{~mm}$ thin aluminum plate with a distance of L (Figure 10). The left was a transmitter with a smoothed $300-\mathrm{kHz}$ tone-burst excitation with a $10-\mathrm{Hz}$ repetition rate to generate the lamb wave in the thin plate. It can be directly connected to an HP33120A function generator which can provide $20 \mathrm{~V}$ peak to peak excitation or connected to a high voltage amplifier which can provide $300 \mathrm{~V}$ peak to peak excitation. The right was a receiver to collect the Lamb wave signal. It can be directly connected to a Tektronix digital oscilloscope or connected to a charge amplifier module first then the oscilloscope. Using equation(5), transmitter PZT-PWAS can generate a Lamb wave of $2 \mu \varepsilon$ strain under $20 \mathrm{~V}$ peak to peak excitation. After the Lamb wave propagates to the receiver PZT-PWAS, the receiver PWAS can generate a $50-\mathrm{mV}$ signal that can be calculated from equation(13).

A complete comparison of PZT-PWAS and PVDF-PWAS in pitch-catch is shown in Table 3. PZT-PWAS and PVDF-PWAS were placed at a distance of $65 \mathrm{~mm}$. High Voltage was selected to use to amplifier the signals.

Table 3 Comparison of PZT-PWAS and PVDF-PWAS in pitch-catch method.

\begin{tabular}{cccccc}
\hline & $\begin{array}{c}\text { Transmitte } \\
\text { r }\end{array}$ & $\begin{array}{c}\text { HV } \\
\text { Amplifier }\end{array}$ & $\begin{array}{c}\text { Input } \\
\text { Voltage(V) }\end{array}$ & Receiver & $\begin{array}{c}\text { Output } \\
\text { Voltage(mV) }\end{array}$ \\
\hline 1 & PZT & N & 17 & PZT & 116 \\
2 & PZT & Y & 57 & PZT & 318 \\
3 & PZT & N & 17 & PVDF & 9.3 \\
4 & PZT & Y & 57 & PVDF & 30.0 \\
5 & PVDF & N & 18 & PZT & 0.96 \\
6 & PVDF & Y & 57 & PZT & 2.1 \\
7 & PVDF & N & 18 & PVDF & N/A \\
8 & PVDF & Y & 250 & PVDF & 0.85 \\
\hline
\end{tabular}

\section{Charge Amplifier Module}

Burr-Brown precision high-speed Difet ${ }^{\circledR}$ operational amplifier OPA627 was selected for its advantage of very low noise and fast settling time. The bandwidth of the operational amplifier is 800 $\mathrm{kHz}$. The PWAS capacitances were measured before and after they were attached to the plate. The free square PWAS capacitances were $3.8 \mathrm{nF}$. After PWAS were bonded to the plate, the capacitances were a little small. The measurement results were $3.25 \mathrm{nF}$ for both PWAS. 


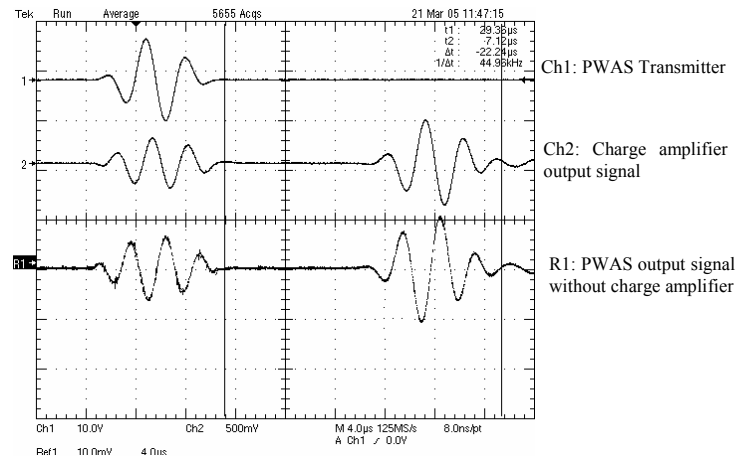

Figure 11 Charge amplifier experiment results.

Figure 11 shows the signal without and with the charge amplifier. Ch 1 is $18 \mathrm{~V}$ peak to peak $300 \mathrm{kHz}$ tone-burst excitation signal. The Lamb wave was generated and propagated in the plate. Without the charge amplifier, the right PWAS received the Lamb wave S0 mode signal with amplitude of $20 \mathrm{mV}$ (R1). With the charge amplifier, the charge amplifier output signal is around $800 \mathrm{mV}$.

The signals in different frequency ranges were measured to determine the efficiency of the charge amplifier. At a low frequency range from $15 \mathrm{kHz}$ to $150 \mathrm{kHz}$, the Lamb wave $\mathrm{A}_{0}$ mode was measured because $A_{0}$ mode was the dominant signal in this range. At a high frequency range from $150 \mathrm{kHz}$ to $800 \mathrm{kHz}$, the Lamb wave $\mathrm{S}_{0}$ mode was measured because $S_{0}$ was the dominant signal in this range. The voltage gain was calculated and compared with the theory value, shown in Figure 12.

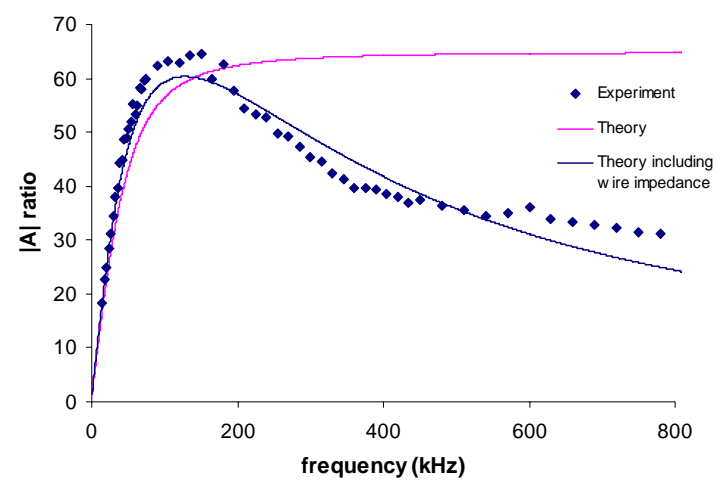

Figure 12 Comparison of the theory and experiment voltage gain after considering the wire impedance.

\section{CONCLUSIONS}

Models of PWAS voltage-stress and voltagestrain have been introduced in this paper. The PWAS actuator generated strain is proportional with the input voltage. The PWAS sensor response is also proportional with the derivative of the strain and stress.
Flexible PVDF-PWAS have been studied with two comparison experiments; cantilever beam free vibration and long rod impaction test. The experimental results of the PVDF-PWAS and strain gauge have been compared with the PZT-PWAS. The theoretical and experimental results of PZTPWAS and PVDF-PWAS performance in this study gave the demonstration of the piezoelectricity of PWAS. Velocity of the wave propagation in an aluminum rod is obtained by applying a strain gauge and PVDF-PWAS on the surface of the rod.

Both PZT-PWAS and PVDF-PWAS are capable of use as a transmitter and receiver in pitch-catch method. PZT-PWAS gives a high voltage response than PVDF-PWAS at the same condition. PVDFPWAS is conformable to curved surfaces and more responsive to higher frequencies.

PWAS are charge mode active sensors and we can use charge amplifier to amplify the signal. The use of a charge sensitive amplifier can reduce the adverse effects of low frequency noise. From the comparison of the theory and experiment results, we can find the charge amplifier is suit for the PZTPWAS working frequency range. The voltage gain is adjustable and the amplification ratio decreased when the frequency became high due to the connection wire impedance.

\section{ACKNOWLEDGEMENT}

The financial support of National Science Foundation award \# CMS 0408578, Dr. Shih Chi Liu, program director, and Air Force Office of Scientific Research grant \# FA9550-04-0085, Capt. Clark Allred, $\mathrm{PhD}$, program manager are gratefully acknowledged.

\section{REFERENCES}

[1] Chang, F.-K. (1995) "Built-In Damage Diagnostics for Composite Structures", in Proceedings of the $10^{\text {th }}$ International Conference on Composite Structures (ICCM-10), Vol. 5, Whistler, B. C., Canada, August 14-18, 1995, pp.283-289

[2] Chang, F.-K. (1998) "Manufacturing and Design of Built-in Diagnostics for Composite Structures", $52^{\text {nd }}$ Meeting of the Society for Machinery Failure Prevention Technology, Virginia Beach, VA, March 30 - April 3, 1998.

[3] Wang, C. S.; Chang, F.-K. (2000) "Built-In Diagnostics for Impact Damage Identification of Composite Structures", in Structural Health Monitoring 2000, Fu-Kuo Chang (Ed.), Technomic, 2000, pp. 612-621

[4] Lin, X.; Yuan, F. G. (2001a) "Diagnostic Lamb Waves in an Integrated Piezoelectric Sensor/Actuator Plate: Analytical and Experimental Studies", Smart Materials and Structures, Vol. 10, 2001, pp. 907-913 
[5] Lin, X; Yuan, F. G. (2001b) "Damage Detection of a Plate using Migration Technique", Journal of Intelligent Material Systems and Structures, Vol. 12, No. 7, July 2001

[6] Ihn, J.-B.; Chang, F.-K. (2002) "Built-in diagnostics for monitoring crack growth in aircraft structures", Proceedings of the SPIE's $9^{\text {th }}$ International Symposium on Smart Structures and Materials, 17-21 March 2002, San Diego, CA, paper \#4702-04

[7] Giurgiutiu, V.; Zagrai, A. (2000) "Characterization of Piezoelectric Wafer Active Sensors", Journal of Intelligent Material Systems and Structures, Sage Pub., UK, Vol. 11, No. 12, December 2000, pp. 959976

[8] Giurgiutiu, V.; Zagrai, A. N.; Bao J.; Redmond, J.; Roach, D.; Rackow, K. (2002) "Active Sensors for Health Monitoring of Aging Aerospace Structures", International Journal of the Condition Monitoring and Diagnostic Engineering Management, UK, Vol. 5, No. 3, August 2002

[9] Giurgiutiu, V.; Bao, J.; Zhao, W. (2003) "Piezoelectric-Wafer Active-Sensor Embedded Ultrasonics in Beams and Plates", Experimental Mechanics, Sage Pub. December 2003, pp. 428-449

[10] Pomirleanu, R.; Giurgiutiu, V. (2003) "Full-Power Dynamic Characterization of Piezoelectric and Magnetostrictive Actuators", Journal of Intelligent Material Systems and Structures, Sage Pub. (in press)

[11] Giurgiutiu, V.; Zagrai, A.; Bao, J. (2004) "Damage Identification in Aging Aircraft Structures with Piezoelectric Wafer Active Sensors", Journal of Intelligent Material Systems and Structures, Sage Pub., Vol. 15, No. 6, June 2004 (in press)

[12] Zhang, Y., "Dynamic Strain Measurement Using Piezoelectric Paint", 4th International Workshop on Structural Health Monitoring, September 15-17, 2003, Stanford University, CA, pp. 1446-1452

[13] Heyliger, p., (2004) ' Two-Dimensional Static Field in Magneto-electro-elastic Laminates', Journal of Intelligent Material Systems and Structure, Vol 15 pp689-709,2004

[14] Benveniste, Y. (1995) 'Magnetoelectric Effect in Fibrous Composites with Piezoelectric and Piezomagnetic phases," Phys. Rev. B., 51: 1642416427

[15] Giurgiutiu, V., "Micromechatronics Modeling, Analysis, and Design with Matlab" CRC Press (2004)

[16] Giurgiutiu, V.; Jichi, F.; Berman, J.; Kamphaus, J. (2001) "Theoretical and Experimental Investigation of Magnetostrictive Composite Beams", Smart Materials and Structures, IOP Publishers, UK, Vol. 10, No. 5, October 2001, pp. 934-945

[17] Measurement Specialties, "Piezo Film Sensors Technical Manual", 1998

[18] Whitney, S., "Vibrations of Cantilever Beams: Deflection, Frequency, and Research Uses", 1999

[19] Voltera, E., Zachmanoglou, E. C. Dynamics of Vibrations. Columbus, Charles E. Merrill Books, Inc., 1965.

[20] Karl F. Graff, Wave Motion in Elastic Solids, N. Y. , 1991
[21] Doyle, J. F., "Impact and Longitudinal Wave Propagation”, Experimental Techniques, 1998.

[22] Hamamatsu, "Characteristics and use of charge amplifier", Solid State Division 